\title{
Examining Decision-Making Regarding Environmental Information
}

\author{
J. L. Marble \\ H. D. Medema \\ S. G. Hill
}

October 2001

Idaho National Engineering and Environmental Laboratory Bechtel BWXT Idaho, LLC 


\title{
Examining Decision-Making Regarding Environmental Information
}

\author{
J. L. Marble \\ H. D. Medema \\ S. G. Hill \\ October 2001 \\ Idaho Falls, Idaho 83415 \\ Prepared for the \\ U.S. Department of Energy \\ Through the INEEL LDRD Program \\ Under DOE Idaho Operations Office \\ Contract DE-AC07-99ID13727
}

Idaho National Engineering and Environmental Laboratory 


\begin{abstract}
Eight participants were asked to view a computer-based multimedia presentation on an environmental phenomenon. Participants were asked to play a role as a senior aide to a national legislator. In this role, they were told that the legislator had asked them to review a multimedia presentation regarding the hypoxic zone phenomenon in the Gulf of Mexico. Their task in assuming the role of a senior aide was to decide how important a problem this issue was to the United States as a whole, and the proportion of the legislator's research budget that should be devoted to study of the problem. The presentation was divided into 7 segments, each containing some new information not contained in the previous segments. After viewing each segment, participants were asked to indicate how close they were to making a decision and how certain they were that their current opinion would be their final decision. After indicating their current state of decision-making, participants were interviewed regarding the factors affecting their decision-making. Of interest was the process by which participants moved toward a decision. This experiment revealed a number of possible directions for future research.

There appeared to be two approaches to decision-making: Some decision-makers moved steadily toward a decision, and occasionally reversed decisions after viewing information, while others abruptly reached a decision after a certain time period spent reviewing the information. Although the difference in estimates of distance to decisions did not differ statistically for these two groups, that difference was reflected in the participants' estimates of confidence that their current opinion would be their final decision. The interviews revealed that the primary difference between these two groups was in their trade-offs between willingness to spend time in information search and the acquisition of new information. Participants who were less confident about their final decision, tended to be the same group of participants who moved slowly toward a decision. These participants also tended to indicate that acquisition of information was more critical than the amount of time spent on the information search. The second group tended to form a set of specific questions for which they desired specific answers. This group was more likely to demonstrate a significant reduction in their distance to a decision much earlier than the first group. In addition, this group tended to be very confident of their final decision and indicated that time spent in information search was more critical than obtaining new information. They indicated that the value of information obtained must remain high to justify the extensive time spent in information search.
\end{abstract}




\section{CONTENTS}

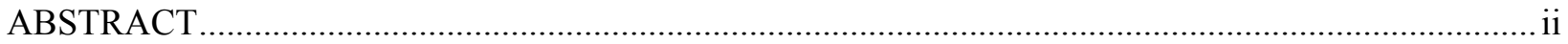

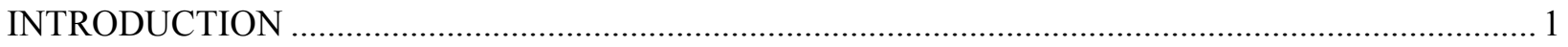

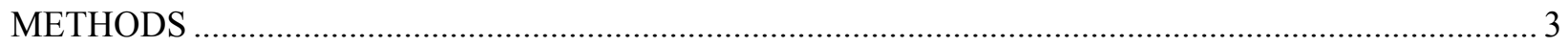

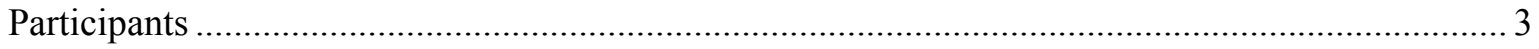

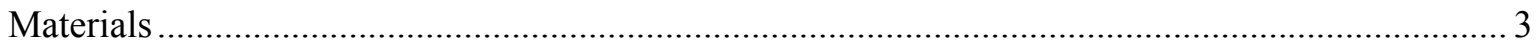

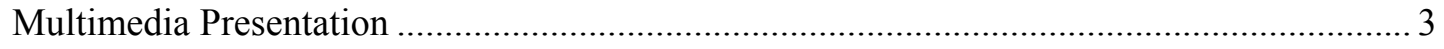

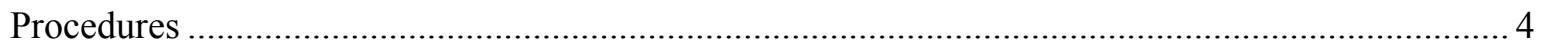

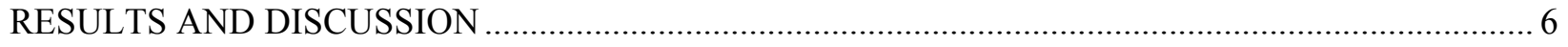

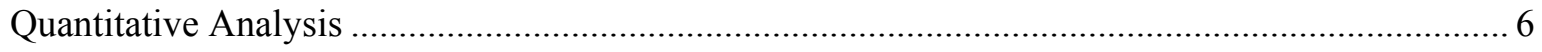

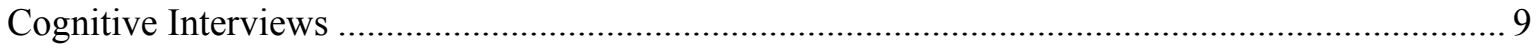

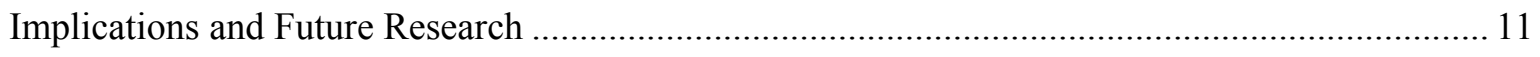

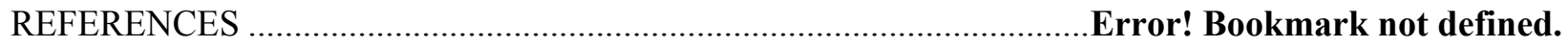

APPENDIX A: Advertisement for Experiment Participants

APPENDIX B: Screen shots of the interactive presentation

APPENDIX C: Consent Form

APPENDIX D: Positive Affect/Negative Affect Assessment Questionnaire

APPENDIX E: New Environmental Paradigm

APPENDIX F: Specific Task Instructions

APPENDIX G: Post-segment Decision Prompt

APPENDIX H: Interview questions

APPENDIX I: Interview transcripts

APPENDIX J: Post-experiment Recommendation task

APPENDIX K: Post-experiment Credibility Questionnaire

APPENDIX L: Post-experiment Demographic Questionnaire

APPENDIX M: Experiment Script and Agenda 


\section{FIGURES}

Figure 1. Mean estimates of confidence in current decision at each decision point for the confident and

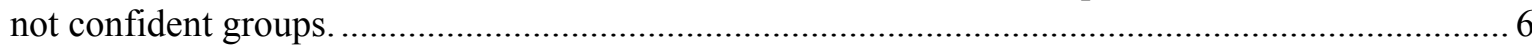

Figure 2. Mean estimates of decision distance at each decision prompt for the confident and not confident

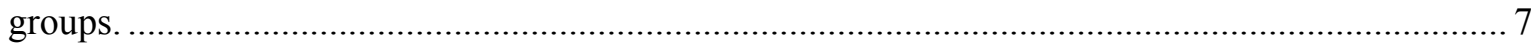

Figure 3. Estimates of decision confidence after segment 6 for confident and not confident groups as a

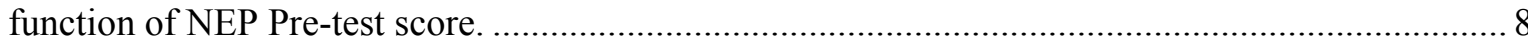

Figure 4. Schematic illustration of willingness to invest more time in information search as a function of the perceived value of the information for the two decision strategy groups................................. 10

\section{TABLE}

Table 1. Description of content and approximate viewing times for each segment of the multimedia

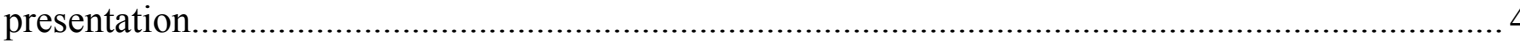




\section{EXAMINING DECISION-MAKING REGARDING ENVIRONMENTAL INFORMATION}

\section{INTRODUCTION}

Decision-making and problem solving are critical aspects of everyday life. Experimental research on decision-making comes from the economics tradition and has focused primarily on expected utility and anticipated regret. Ecological research has focused on consumer behavior. Less research has concentrated on how people make decisions regarding environmental issues, or on issues that have a high perceived value to themselves. In addition, there is not much research on the actual process and time course of decision-making. Finally, research on the role of emotion in decision-making has centered primarily on depression or other clinical issues, rather than how emotional involvement in the topic affects the decision-making process. The present experiment examines the process and time course of decision-making regarding an environmental issue. Further, the type of decision-making strategy used is related to the decision-makers' attitudes regarding the environment both before and after the decision was made.

Concurrent research (Byers, Hill, Harbour, Blackman, \& Medema, 2001) investigated participants' attitudes toward environmental information as a function of presentation format. Information regarding an environmental issue was presented either as a paper-based text description, as a web page, or in a computer-based multimedia presentation. Participants were asked to review the information, indicate their perception of the severity of the issue, and then were tested for comprehension of the material. This led to questions regarding the actual process of decision-making; exactly how much information does a person require before they are able to make a decision? In addition, it was not clear whether this process of information acquisition is the same for all people, or for all information domains.

In the psychological research literature, it has long been known that people do not make consistent, rational (in the economic sense) decisions; rather, they are strongly affected by the framing of the problem and their prior experiences. This has led to the distinction between utility and expected utility theories (Kahneman \& Tversky, 1990, 2000). Other factors also affect people's ability to make decisions. Santos-Gomez (1991) found that the manner in which information was presented significantly affected participants' ability to select optimal information during decision-making. Participants who did not receive explicit descriptions of categories were unable to select information to distinguish between the categories optimally during a later test.

Literature on information search and acquisition tends to follow the economics tradition, which assumes that search continues as long as the perceived marginal benefits of acquiring additional information exceed the cost of acquisition, or game-theory, which examines decision-making under risk. A basic tenet of economics-based decision research is the sequential-sampling model (Wald, 1947), which suggests that information is acquired until the evidence in support of the working hypothesis exceeds some preestablished criterion. In a test of this model, Saad and Russo (1996) examined the stopping criteria that college students used to determine when they had sufficient information to pick the 'best' apartment based on descriptions. They concluded that when there is accumulation of cost or poor

progress for acquiring information, the students adapted behavior by reducing the acceptable threshold for a decision. In other words, when the ratio of the value of the information obtained and the time spent obtaining information was small, the students tended to lower their stopping point for obtaining information and 'settle' for less information or less valuable information.

Research on selective exposure to information consistently demonstrates that after having made a decision, people prefer supporting information to conflicting information (Jonas, Schulz-Hardt, Frey \& 
Thelen, 2001; Wason \& Johnson-Laird, 1970). This preference is known as confirmation bias. Recently, Jonas et al. demonstrated that confirmation bias is increased when information is presented and processed sequentially rather than simultaneously. The authors argued that this strengthened preference for consistent information is caused by enhanced commitment to the decision and escalated focus on the decision.

Game-theory research into decision-making has used gambling scenarios to investigate the effects of risk and consequence on decisions. Game theory explores rational behavior for interactive decision problems. In a game, several agents strive to maximize their (expected) utility index by choosing particular courses of action, and each agent's final payoffs depend on the profile of courses of action chosen by all agents. The interactive situation, specified by the set of participants, the possible courses of action of each agent, and the set of all possible utility payoffs is called a game; the agents 'playing' a game are called the players.

Although the principles uncovered in such research certainly apply to more common decision scenarios, this type of research ignores the process by which people actually make decisions. It is unclear how much information people normally acquire before they are able to make decisions. In addition, it is unclear whether there are one or many processes used to reach a decision. Finally, it is questionable how receptive people are to reversing a decision once they have begun to make a selection. If people do not reverse a decision after initial consideration, it would be important for an institution seeking policy support to present the best argument as the initiation to the topic.

Research into factors that affect decision-making is critical to internal DOE activities, as well as to interactions between DOE and stakeholders. Stakeholders typically have begun to form an opinion or make a decision by the time that DOE presents relevant information. In interactions with the public, DOE assesses the probability of adverse consequences, and presents this risk information. Stakeholders make decisions regarding whether or not to support DOE proposals based on factors that include risk, but which also include factors such as prior experience and the perceived value of the item at risk. The greater the perceived value of the at-risk item, the less likely the public will be willing to accept this risk.

The following experiment explored the process by which people acquire information on a novel environmental topic before making a decision regarding the topic. The relation of decision-making to general attitudes toward the environment, and positive and negative affect were examined. Of particular interest were the amount of time the decision-makers spent before reaching a decision, whether this point would be similar for all decision-makers, and whether any decision-makers demonstrated reversals of their decision after acquiring new information.

Also of interest was how decision-making strategy varied as a function of environmental attitudes, assessed through the revised New Environmental Paradigm questionnaire (NEP; Dunlap \& Van Liere, 1978; Dunlap, Van Liere, Mertig, \& Jones, 2000). We were also curious whether there would be any change in environmental attitude before and after the presentation. 


\section{METHODS}

\section{Participants}

All subjects were recruited by advertisement in the Engineering Research Office Building and Willow Creek Building. The advertisement is presented in Appendix A. Eight employees of the Idaho National Engineering and Environmental Laboratories (INEEL) elected to participate. Six were male, and two were female. Participants were workers in the town of Idaho Falls. Mean age of the participants was 45.75 years, with a range of 32 to 53 years. Median education was Bachelor's degree. All participants had a technical or scientific background. By self-report, three indicated a 'liberal' political ideology, and five indicated a 'conservative' ideology. Participants were paid their normal salaries for participation.

\section{Materials}

The PC used was a Dell Precision ${ }^{\mathrm{TM}} 620$ with dual Intel ${ }^{\circledR}$ Pentium III ${ }^{\circledR} \mathrm{Xeon}^{\mathrm{TM}}$ microprocessors, $^{\mathrm{T}}$ using the Microsoft Windows 2000 operating system. The monitor was a 21" IBM 6558 P202 set at a resolution of $800 \times 600$. The monitor was set for an $85 \mathrm{~Hz}$ refresh rate and true color. The video card was a GeForce 2 GTS/Pro. Both the keyboard and mouse were cordless - the Logitech iTouch cordless keyboard and Logitech iTouch cordless wheel mouse, respectively.

The multimedia application was a custom-built software application, created using Macromedia Director 7 Shockwave Studio. The interface application was created in HTML and called Winamp to present audio files. In the multimedia application, the user did not have unlimited navigational power. All users started with the same segment, which was followed by a menu page that presented a button to repeat the segment just viewed and two buttons for different unviewed segments from which the user could pick the path forward. A similar menu was presented after every segment, with a button for the segment just viewed added to the other review buttons, and two buttons for yet unviewed segments that allowed the user a limited choice of which path to take forward. (See Appendix B.) If any segment was repeated, the program returned the user to the menu from which the repeat had been called upon completion of the replay. Segments lasted between 1 and $10 \mathrm{~min}$. Uninterrupted viewing of the presentation took approximately $28 \mathrm{~min}$. Viewing of the presentation, including time between segments for the interviews, lasted approximately 1 hour. Each experimental session lasted 1 1/2 to 2 hours.

\section{Multimedia Presentation}

The multimedia presentation discussed the topic of eutrophication and its relation to the seasonal hypoxic zone phenomenon in the Gulf of Mexico region of the US. All information presented in the presentation was scientifically accurate and obtained from published sources. No effort was made to present a particular point of view or to persuade viewers to a given point of view. Table 1 gives a brief description of each segment and its approximate viewing time. 
Table 1. Description of content and approximate viewing times for each segment of the multimedia presentation.

\begin{tabular}{|l|l|l|}
\hline \multicolumn{1}{|c|}{ Segment Title } & \multicolumn{1}{|c|}{ Description } & \multicolumn{1}{|c|}{$\begin{array}{l}\text { Approximate } \\
\text { Viewing time }\end{array}$} \\
\hline Hypoxic Zone & $\begin{array}{l}\text { Introduction to the phenomenon. It is defined by a lack of oxygen } \\
\text { in water. Area of the phenomenon has been increasing for past 12 } \\
\text { years. }\end{array}$ & 3 min \\
\hline Jubilee & $\begin{array}{l}\text { A rare phenomenon occurring in late summer in the Gulf of } \\
\text { Mexico. Fish move onto land trying to escape the low oxygen } \\
\text { (hypoxic) areas, and are harvested by local residents. }\end{array}$ & 4 min \\
\hline Algae Growth & $\begin{array}{l}\text { Abundant nutrients allow large increases in algae populations. } \\
\text { Increases in algae allow corresponding increases in the microbes } \\
\text { that feed on algae. }\end{array}$ & 2 min \\
\hline Nutrient Sinks & $\begin{array}{l}\text { Prior to damming of the Mississippi River, marsh deltas reduced } \\
\text { the amount of fertilizers and other nutrients that reached the Gulf, } \\
\text { preventing population explosions of microorganisms. }\end{array}$ & 5 min \\
\hline Nutrient Supply & $\begin{array}{l}\text { Damming of the river has increased the amount of fertilizer that } \\
\text { reaches the Gulf of Mexico. Individual farmers are not major } \\
\text { contributors. However, the effects are cumulative. }\end{array}$ & 5 min \\
\hline Eutrophication & $\begin{array}{l}\text { Increases in algae cause explosions in the populations of } \\
\text { microorganisms that feed on algae. As these animals die, oxygen is } \\
\text { removed from water by their decay. } \\
\text { water mixing, such as salinity, wind, and temperature. }\end{array}$ & 6 min \\
\hline
\end{tabular}

The hypoxic zone is a phenomenon that occurs most summers in the Gulf of Mexico. Decay of algae and algae-feeding bacteria removes oxygen from the water until the area becomes a low oxygen or hypoxic zone. At a critical point, fish and marine creatures can no longer obtain sufficient oxygen from the water. Therefore, they attempt to leave the area of hypoxia, which sometimes means swimming or crawling onto the shore. This is known in the Gulf States as the Jubilee, during which local residents collect the readily available fish from the shore. Increases in fertilizer use, algae growth, reduced filtering of the Mississippi River through marshland, low levels of wind, and changes in temperature and salinity all contribute to the occurrence of hypoxic zones. These issues were covered in the multimedia presentation.

\section{Procedures}

At the beginning of the experimental session, participants were informed of the general purpose of the experiment, and asked to read and sign a Participant Informed Consent form (See Appendix C). Next, they were asked to complete the Positive and Negative Affect Survey (PANAS; Watson, Clark, \& Tellegen, 1988; see Appendix D), and then the revised New Environmental Paradigm questionnaire 
(NEP; Dunlap \& Van Liere, 1978; Dunlap, Van Liere et al., 2000; see Appendix E). After completing these two questionnaires, participants were given a written copy of the scenario instructions (see Appendix F), including the questions for which they were asked to make a decision. Participants were encouraged to refer to these specific instructions throughout the experiment.

Participants were asked to play a role as a senior aide to a national legislator. In this role, they were asked to view a presentation on the eutrophication phenomenon in the Gulf States. Their task in assuming the role as senior aide was to decide how critical an issue this phenomenon was to the United States as a whole and how much of the legislator's research budget should be directed toward these issues. Participants then viewed a computer-based multimedia presentation on the eutrophication and jubilee phenomena in states around the Gulf of Mexico in the United States. The presentation outlined the relationship of farming in the Mississippi River basin and the effects of river control, fertilizer pollution, and damming on the phenomena.

Participants selected a segment for viewing by single clicking on a labeled button with the mouse. After viewing a segment, the participant indicated how close they were to making a decision (henceforth, decision distance) and how confident they were that their current decision would be their final decision by circling one of 11 vertical lines on a bar. (See Appendix G.) Participants were then interviewed regarding their thought processes regarding the information presented in the last segment, and the 'distance' they were from a decision. The questions used in this interview are listed in Appendix H. Not all questions were asked during each interview. Each interview session lasted approximately 5 to 10 minutes after which the participant was allowed to select the next segment of the presentation to view. If a participant wished to review a segment, this occurred before they indicated their proximity to a decision and participated in the interview session. Transcripts of the interview sessions can be found in Appendix I.

After viewing the final segment and completing the final interview session, participants rated their perception of the importance of the issue to the United States as a whole. They indicated how much, if any, of the legislator's research budget they would recommend to be used in researching the issue. Next, participants were asked to answer a number of open-ended questions regarding their recommendations.

(See Appendix J.) After completing these questionnaires, participants again filled out the PANAS and the NEP. Finally, participants completed three questionnaires regarding the likeability and credibility of the presentation. (See Appendix K.) Participants then filled out a few brief questions on demographics: Age; occupation; and political ideology. (See Appendix L.) At the conclusion of the experimental session, participants were debriefed and any questions they had regarding the purpose of the experiment or presentation were answered. Appendix M contains the Experiment Script and Agenda. 


\section{RESULTS AND DISCUSSION}

Few participants were solicited for this experiment for two primary reasons. First, this experiment was intended as a pilot study to uncover new areas of research in decision-making for which little research has been done. Secondly, it was also employed to investigate the usefulness of the cognitive interviewing method in decision-making research. This was the first application of the cognitive interviewing method at the INEEL. The interaction with the participants during the interviews led to a greater understanding of their process for reaching a decision than could have been achieved using less interactive methods. Interviews of the participants indicated further areas for inquiry, which could be followed up with immediately. Most participants did not appear uncomfortable during the interviews, although several did learn to anticipate specific lines of questioning. This method may prove useful in other preliminary research to uncover areas for investigation.

\section{Quantitative Analysis}

These analyses did not reveal many significant effects, which is not surprising given the small number of participants tested, and therefore the low statistical power. However, the trends indicate a number of interesting relationships. Examination of the confidence estimates at the final decision point (prompt 7) indicated that the participants were divided into two groups: Those who were $100 \%$ confident that their opinion after the seventh segment would be their final opinion; and those who were less than $100 \%$ confident. A Tukey HSD test indicated that this difference was significant, $F^{*}=3.64, M S E=$ $0.0295, p<0.05$. The mean reported confidences for the two groups were $100 \%$ and $62.5 \%$ at the final decision prompt. (See Figure 1.)

Confidence in Decision

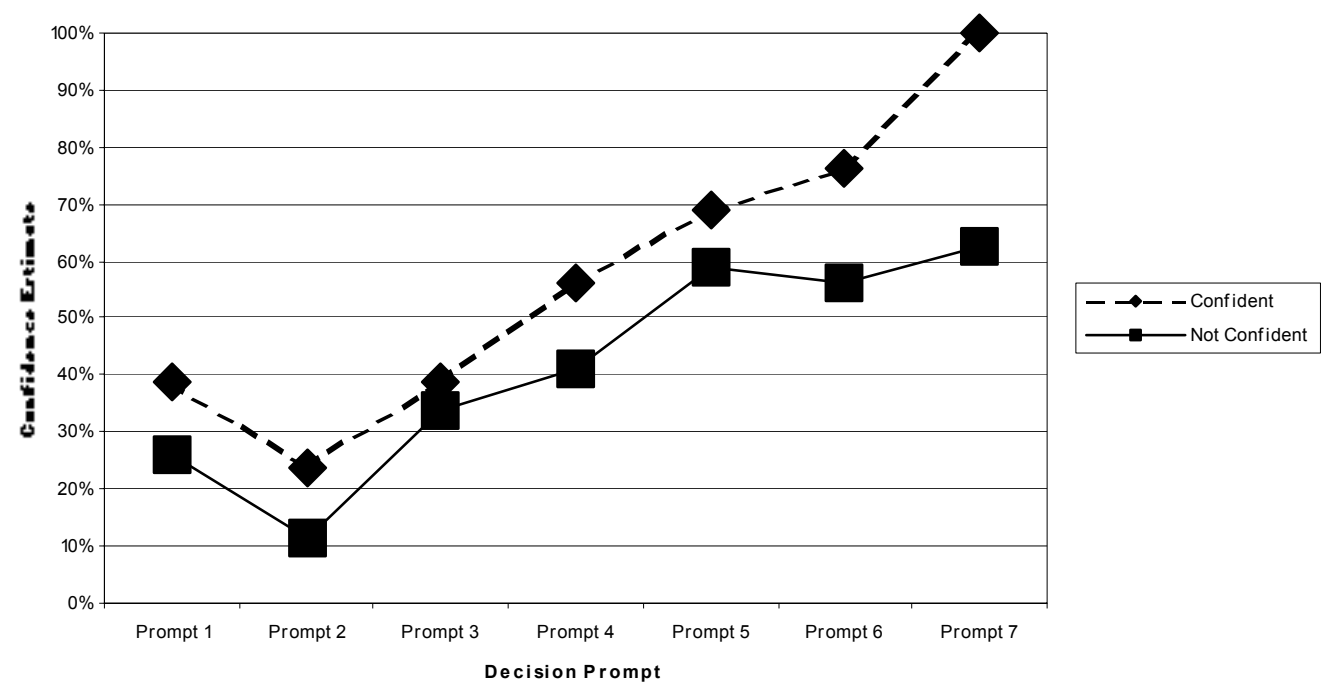

Figure 1. Mean estimates of confidence in current decision at each decision point for the confident and not confident groups. 
This natural demarcation was used to divide the data from the participants into two separate groups for analysis. Using final confidence as a grouping variable, a general linear regression model was run on the data to investigate whether there were differences in responses to the decision prompts. The responses to decision prompts were also analyzed with respect to positive and negative affect and environmental attitude before and after the presentation.

Most important for the following discussion, the two groups did not differ in their estimates of how close they were to a decision (henceforth, decision distance) at the first prompt, $F<1.0, p=0.5163$. (See Figure 2.) This similarity of decision distance between groups is important because it indicates that later differences cannot be attributed to differences in initial estimates of decision distance. Given the few participants who took part in the experiment, it is not surprising that the regression analysis did not indicate differences in responding as a function of final confidence. However, it was interesting to note that although not significant the strength of the difference between the groups increased at the final decision point, $F=4.19, p=0.1$. This would imply that replication of this experiment with more participants could indicate differences in decisions as a function of confidence.

\section{Distance from Decision}

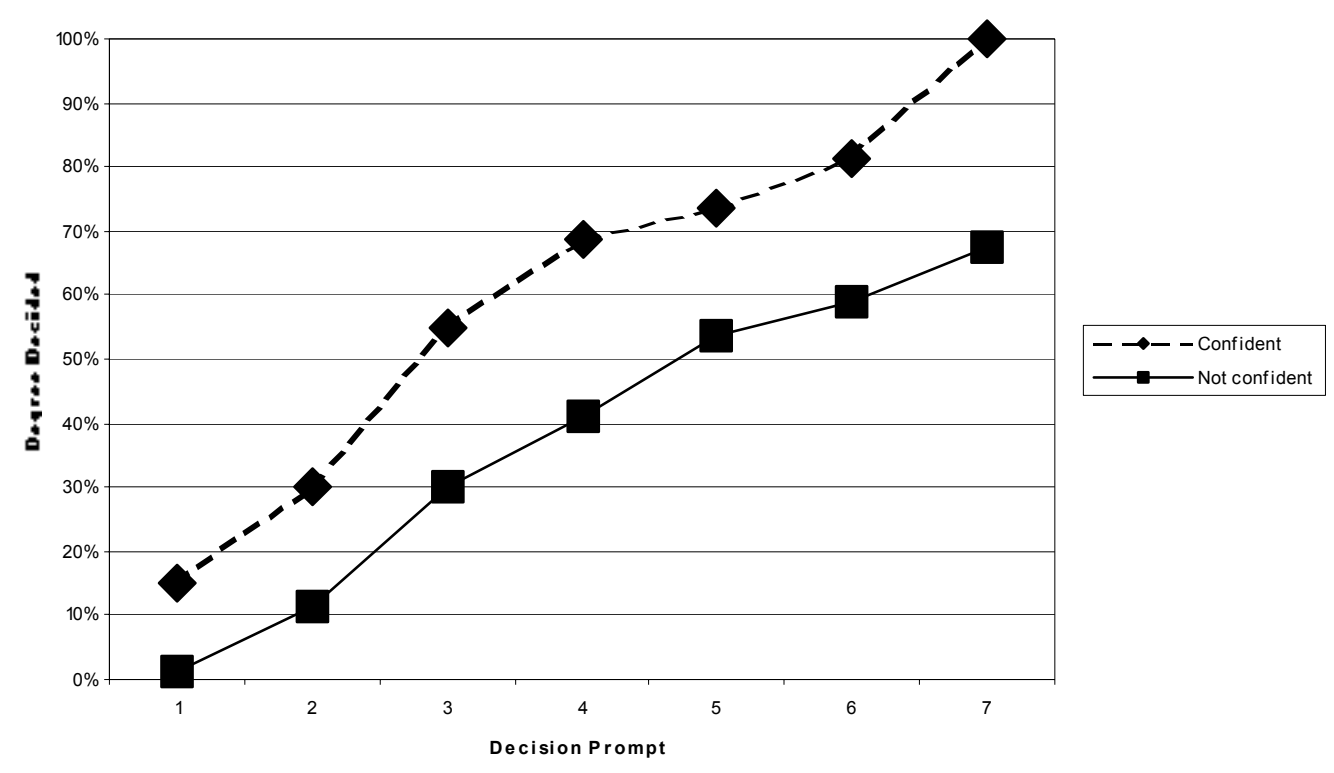

Figure 2. Mean estimates of decision distance at each decision prompt for the confident and not confident groups. 
A significant interaction of the pre-test NEP score with decision confidence at decision prompt 6 was found, $F(2,7)=6.05, M S E=0.016, p>0.047$. Higher initial environmental attitude scores, as assessed by the NEP, were related to decreases in confidence at decision prompt 6. (See Figure 3.) This difference continued as a non-significant tendency at decision prompt $7, F=4.85, p=0.0674$. This lack of significance could partially be due to the participants' awareness that they had seen the final segment and knowledge that they would next make their final decisions. However, the cognitive interviews would tend to support the tendency of a difference between groups, because less confident participants tended to indicate that if they knew that there was more information available, that it would reduce their confidence rating or distance to a decision.

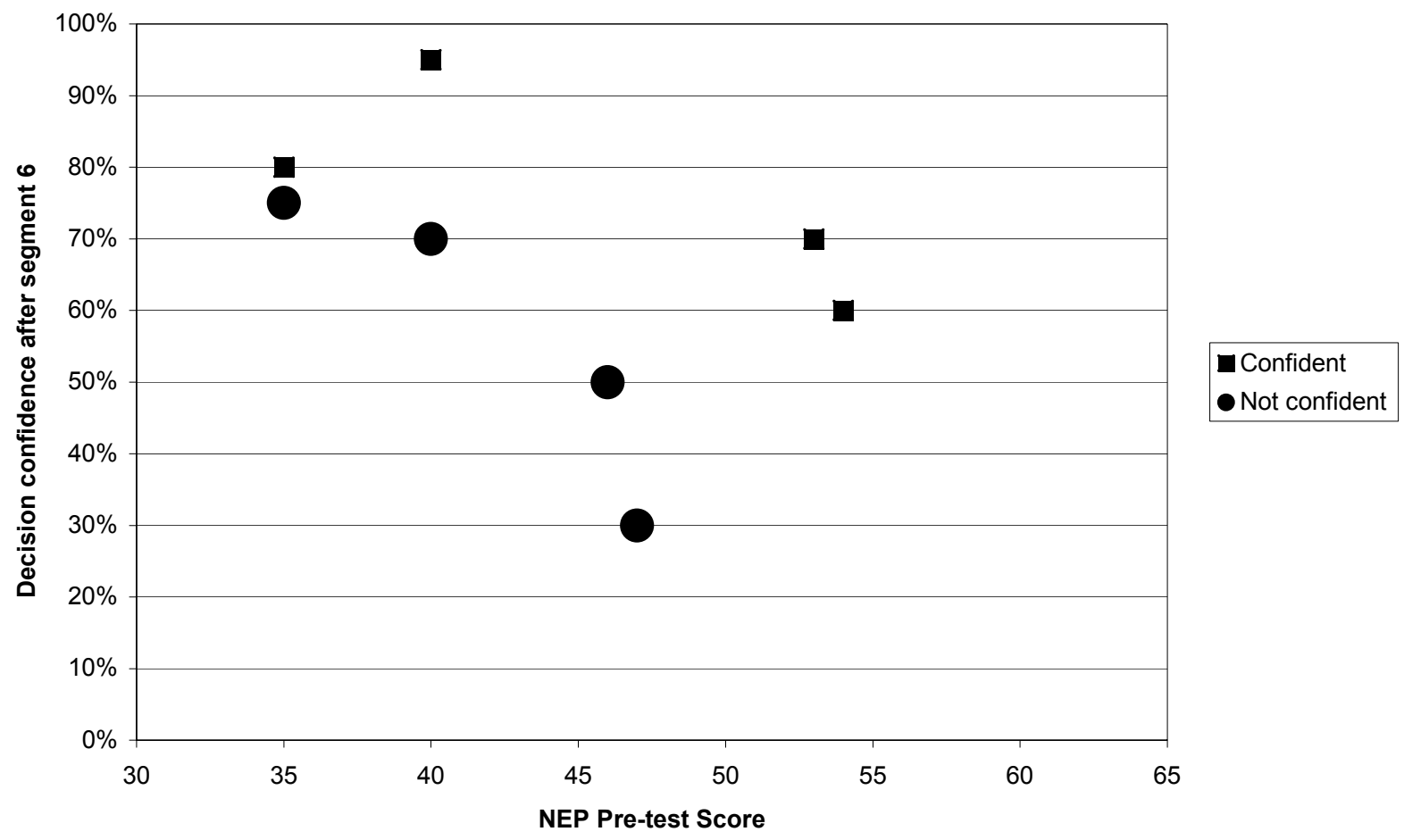

Figure 3. Estimates of decision confidence after segment 6 for confident and not confident groups as a function of NEP pre-test score.

There were no effects of positive or negative affect on the decision making process. Nor were there any significant changes in positive and negative affect or the NEP pre- and post-test scores. Finally, there were no differences in pre- or post-test affect scores as a function of decision confidence at the final decision prompt. No differences in the ratings of problem importance or the proportion of the budget that participants recommended for study of the problem based on the confidence distinction were found. Nor was there a significant difference on the participants' confidence rating for these decisions based on their confidence at decision prompt 7. 


\section{Cognitive Interviews}

Interviews with the participants between presentation segments seemed to indicate two distinct information acquisition strategies apparent within the participant group. The participants appeared to be split between three who indicated frustration that they were not obtaining information they felt was most valuable in a timely fashion (the jumpers), and three who felt that acquisition of any information was important (the creepers). Two were not easily classified into these categories.

The first group (the jumpers) typically made a large jump to almost $100 \%$ decision completion by the end of the fifth segment in the presentation. In addition, this group tended to be $100 \%$ confident that their opinion would be their final decision at the final decision prompt (prompt 7). The jumpers on average indicated that there were specific questions or pieces of information that they were looking for. In addition, they were more likely than the creepers to indicate that they did not believe that they would receive this information from the presentation. Specifically, this group of participants appeared to more strongly value the time sunk into the information search than the acquisition of new information.

The second group (the creepers) characteristically indicated that they were not looking for specific information; rather that they needed 'more information' in order to be able to make a decision. It was interesting to note that two subjects who appeared to follow this decision strategy admitted that they had revised and reversed their decisions after receiving new information in the presentation. (By reversed, we do not mean that the distance to the decision increased. Rather we mean that the participant indicated during the interview that their current opinion was no longer consistent with their previous opinion.) This group tended to indicate that the acquisition of more information was more important that the amount of time that they spent acquiring it. This second group approached a decision more slowly than the first. Their confidence that their current opinion would be their final opinion increased at the same rate as their distance to a decision decreased across decision prompts. In addition, they tended to be the same group who did not indicate $100 \%$ confidence that their opinion would be their final decision at the seventh decision prompt. Generally, they more strongly valued the acquisition of new information than the time spent gathering the information. (See Figure 4 for a graphic representation of this difference.) 


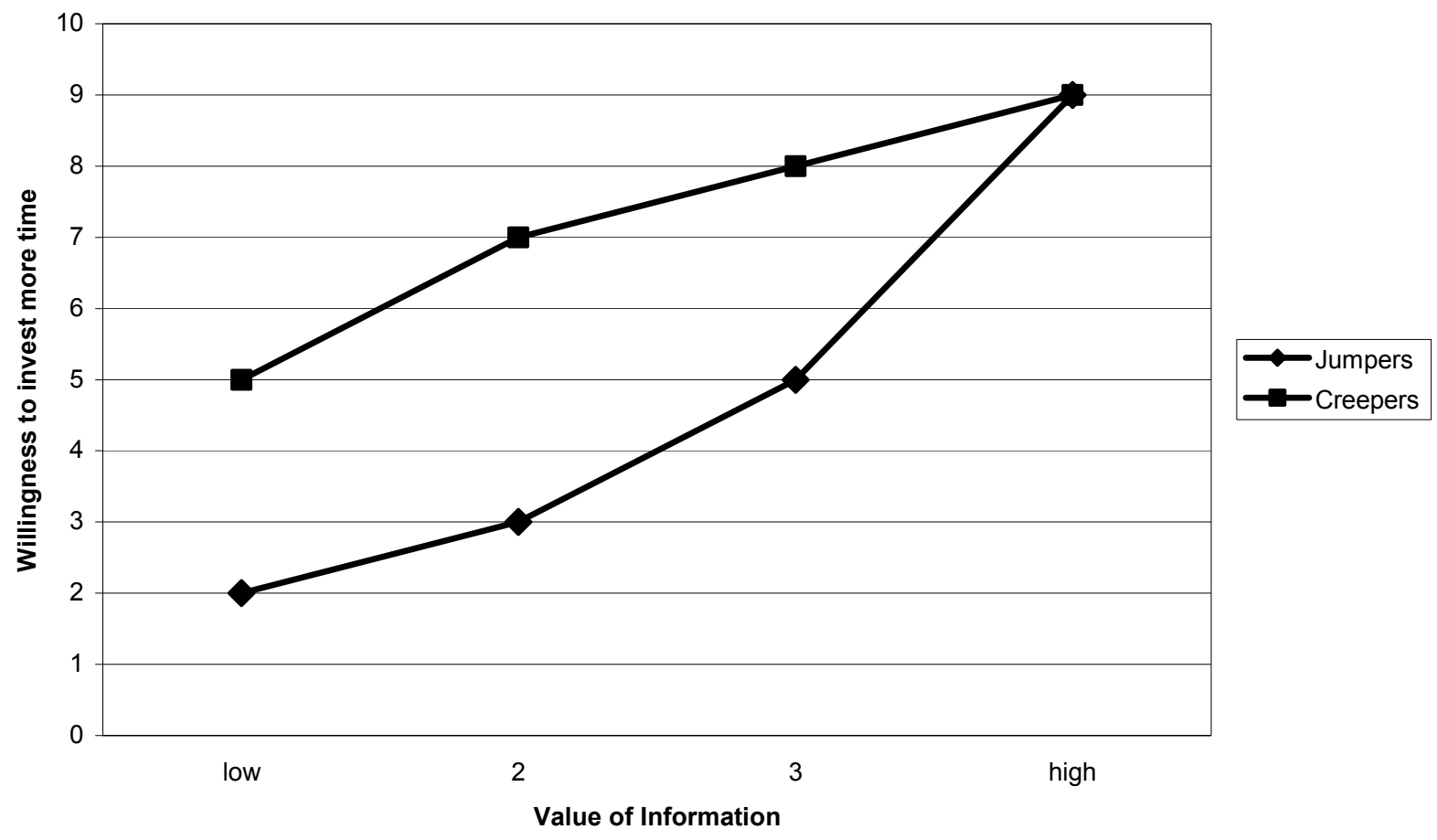

Figure 4. Schematic illustration of willingness to invest more time in information search as a function of the perceived value of the information for the two decision strategy groups.

Wason and Johnson-Laird (1970) indicated that people prefer information that is consistent to their hypotheses to information that is disconfirming, once a decision has been formed. Although this experiment was not designed to explore this hypothesis, it was interesting to note that at most inquiry points the participants indicated they were 'just looking for more information.' However, at a few inquiry points participants did admit that they were looking for information to confirm (or at least be consistent with) their current opinion. One participant did admit that he was hoping for information to disconfirm his opinion. These results imply that the preference for compatible information is not an active information strategy.

There was significant variance in the answers between the groups when participants were asked whether they perceived a tradeoff between the time spent obtaining information and the value of information obtained. The jumpers valued the time spent more highly than obtaining new information, while the creepers felt that acquiring new information justified the time spent. This was reflected in their answers as to whether their rating of confidence and distance to a decision would change if there were more information available during the final interview session. The creepers indicated in the final interview session that if there were more information or segments in the presentation, their indication of confidence or decision completion would be reduced. While the jumpers typically stated that their ratings would not change much if any, a few indicated that generally only their confidence ratings would change.

The time spent versus information value tradeoff difference between the two groups was also reflected by the fact that the jumpers were more likely to indicate that they would be willing to stop 
before the end of the presentation and make a decision. One such participant indicated there was specific information that he wished to acquire, but he did not think he would get from the presentation. If he were certain he would not get that information, he would be willing to stop viewing the presentation at that point and make a decision. In contrast, one participant who followed the creeper strategy indicated he would want to view the presentation in its entirety, if for no other reason than that the makers of the presentation had put a lot of work into it, and he would want to hear what they had to say.

Creepers indicated they would be willing to view more segments of the presentation after the final segment was complete. They typically did not indicate that they desired specific information. Jumpers, on the other hand, characteristically expressed desire to know the answers to specific questions about the information contained in each segment. After the final segment, jumpers tended to indicate they would only be willing to watch more segments if they knew what those segment were about and could pick and choose which they viewed, or if they knew that those additional segments would answer their specific questions.

Also of interest was certain participants' tendency to disbelieve segments due to their content. This was seen explicitly in three participants. Two inquired of the experimenter whether the hypoxic zone and eutrophication phenomena were real. The third participant, during and after viewing the segment on the damming of the Mississippi River, indicated suspicion of the inclusion of an 'interview' with an Army Corps of Engineers 'member'. He commented that this inclusion could be propaganda included to sway the decision-maker. This participant also expressed sarcasm toward the Army Corps of Engineers' ability to build dams, and the need for the Corps of Engineers to consider the consequences of their actions in advance.

\section{Implications and Future Research}

These findings have various implications for presentation of information. Most important would be the need to identify the information that the audience would most desire after a brief introduction to the topic. This information needs to be presented quickly. There is an advantage to allowing the audience to determine what information they obtain. This means that presentations should contain brief overviews of the contents of each segment. Doing so allows the audience to make informed choices regarding how to progress through the presentation. However, these conclusions are all basic to good writing habits.

The most critical implication of these findings is that there may be two decision strategies adopted when people are presented information. These results also imply that decision makers rarely reverse their initial opinion when presented with more information later. Rather than change their opinion, there was indication that the decision-maker will find reasons to discard that new information. This was apparent with Participant 8, who obtained late in the presentation information that he had desired, but then decided that it was necessary to reduce the scope of the questions he was answering. This may have allowed him to discard the information he had obtained, rather than reverse his decision. Such actions would be consistent with the above-mentioned finding of Wason and Johnson-Laird (1970) that people prefer information that is consistent with their hypotheses to that which is contradictory.

This finding also indicates that what people bring into a situation, i.e., their preferred decision making strategy, their political ideology or environmental attitudes, may be more important than the arguments presented. Few participants reported reversing their decisions when presented with new

\footnotetext{
${ }^{1}$ All roles in the presentation were played by actors. Participants were informed before beginning the presentation that these people were actors, and that this was not an attempt to mislead or confuse them in anyway.
} 
information. Participants who valued time spent more highly than the acquisition of new information tended to create a working hypothesis that drove their decision early in the presentation of information. This hypothesis drove their decision until they passed a time-based criterion to make a decision. After that critical time had passed, they were much less willing to consider new information and were reasonably certain of their decision.

These findings lead the research into the realm of persuasion: Are there ways to reduce or avoid the confirmation bias in decision-makers? Specifically, it would be useful to explore what methods of presenting information or what context of information allows the decision-maker to consider alternate hypotheses. In addition, it would be useful to investigate whether it is possible for a decision-maker to consider multiple decision options at a given time.

Ultimately, the primary difference between the groups was in the criterion they used to reach a decision. The creepers, who tended to be less confident in their final decision, appeared to use an information-based criterion to drive their decision. Their decision was not final until a pre-set amount of information was acquired. This criterion may not have been reached by the presentation, which was short and did cover some points multiple times. The jumpers, who seemed much more confident in their final decision, appeared to use a time-based criterion. That is, information was acquired until they felt they had spent 'enough' time in information acquisition at which time they were prepared to make a decision.

Further research is needed to determine whether this difference in decision styles is an accurate reflection of the population. It will be necessary to replicate this experiment with a much larger sample to determine whether the conclusions here are reliable. Of interest would be to examine how much information people choose to acquire before making a decision. It would be useful to investigate whether there is one segment of the population that typically acquires much less information before making a fully confident decision than another segment of the population. It would also be critical to investigate whether, for one segment of the population, confidence in a decision is a function of the time spent obtaining information.

It is probable that the indications of distinct decision-making strategies may be domain or experience dependent. It is possible that in domains in which decision-makers have more experience, they will demonstrate more affinity for and greater effects of a preferred decision-making strategy. It may also be found that more affinity for a certain decision strategy is found in domains for which the decision-maker has a stronger affective reaction. That is, topics for which the decision-maker has a stronger initial emotional reaction may lead to greater usage of a particular decision style in the population.

Related to this may be the finding that decision confidence appeared to be inversely related to higher scores on the NEP in the pre-test stage. It may be that people who perceive a greater value to the topic in question choose to implement different decision strategies than those who perceive the topic as less valuable. In this case, participants who demonstrated a greater perceived value for the environment also indicated less confidence in their final decision for questions that could impact the environment. Finally, future research should also investigate whether political ideology varies with these decisionmaking strategies. 


\section{REFERENCES}

Byers, J., Hill, S., Medema, H., Harbour, G. \& Blackman, H. (2001). Presenting Environmental Information Using Paper, Web and Multimedia Formats (INEEL/EXT-01001303). Idaho Falls, ID: INEEL.

Dunlap, R., \& Van Liere, K. (1978). The "new environmental paradigm": A proposed measuring instrument for environmental quality. Social Science Quarterly, 65, 1013-1028.

Dunlap, R., Van Liere, K., Mertig, A., \& Jones, R. E. (2000). Measuring enforcement of the new ecological paradigm: A revised NEP scale. Journal of Social Issues, 56, 425-442.

Jonas, E., Schulz-Hardt, S., Frey, D., \& Thelen, N. (2001). Confirmation bias in sequential information search after preliminary decisions: An expansion of dissonance theoretical research on selective exposure to information. Journal of Personality and Social Psychology, 80, 557-571.

Kahneman, D., \& Tversky, A. (1990). Prospect theory: An analysis of decision under risk. In P. K. Moser (Ed.), Rationality in action: Contemporary approaches. (pp. 140-170). New York, NY: Cambridge University Press. 493 p.

Kahneman, D., \& Tversky, A. (Eds.) (2000). Choices, values, and frames. New York, NY: Cambridge University Press. 840 p.

Saad, G., \& Russo, J. E. (1996). Stopping criteria in sequential choice. Organizational Behavior and Human Decision Processes, 67, 258-270.

Santos-Gomez, L. (1991). Knowledge acquisition and information searching strategies in diagnostic decision making. Acta Psychologica, 77, 293-305.

Wald, A. (1947). Sequential analysis. New York, NY: John Wiley. 212 p.

Wason, P. C., \& Johnson-Laird, P. N. (1970). A conflict between selecting and evaluating information in an inferential task. British Journal of Psychology, 61, 509-515.

Watson, D., Clark, L. A., \& Tellegen, A. (1988). Development and validation of brief measures of positive and negative affect: The PANAS scales. Journal of Personality and Social Psychology, 54, 1063-1070. 
Appendix A

Advertisement for Participants 


\section{APPENDIX A: Advertisement for Experiment Participants}

This notice was sent via company email to employees in the EROB and WCB buildings.

\section{Wanted: Participants in Human-Centered Research}

Would you like to do something fun at work?

Come and participate in some human-centered research!

The Human Systems Department (located on the first floor of EROB) will run experiments in June beginning the middle of next week. These experiments will look at the effects of different presentation formats on communications.

We need help from EROB and WCB employees. If you are able to participate for $1 \frac{1 / 2}{2} 2$ hours total, please reply to this note. Within your response, please include:
Name:
Phone number:
Age Group:
Under 20
20-29
30-39
40-49
50-59
60-69
70-79
Above 79

We are asking that participants indicate which age group they fall under in order that we may gather a representative sample of data. We are by no means disqualifying interested parties, but rather, we would like to ensure that we have scheduled adequate participants for each age group.

We will contact you, tell you more about the research and schedule a time for your participation. Please note that we will provide a charge number for your participation in these studies.

Thank you 
Appendix B

Screen Shots of Multimedia Presentation 


\section{APPENDIX B: Screen shots of the interactive presentation}

Hypoxic Zone

* Jubilee

\section{*Eutrophication}

\section{An Unusual} Event In The Gulf Of Mexico

\section{Click Any Button}

To Continue

Figure 1. Screen shot of choice screen. All participants first viewed the 'Hypoxic Zone' segment, then were present the first two possible choice segments. Unchosen segments are indicated by stars. As shown in the figure, segment options appeared in pairs. Segments that were not selected were represented with a new alternative after other segments were viewed. 
Hypoxic Zone

\section{Jubilee}

Algae Growth

\section{An Unusual} Event In The Gulf Of Mexico

Nutrient Sinks

Nutrient Supply

Water Mixing

Click Any Button To Continue

Figure 2. Buttons indicating titles of all segments in presentation. 
Appendix C

\section{Participant Consent Form}




\title{
APPENDIX C: Consent Form
}

\section{Idaho National Engineering and Environmental Laboratory RESEARCH SUBJECT INFORMED CONSENT FORM}

\author{
Prospective Research subject - Please read this consent form carefully and ask as many \\ questions as you would like before you decide whether you want to participate in this research \\ project.
}

Project Title: INEEL Human-System Simulation Enterprise: Multimedia and Decision Making Using a Scientific Information Task About Eutrophication

\section{Project No.: INEEL-IRB-2001-}

Sponsor: LDRD-URC

Principal Investigator: Susan Hill Phone: 526-0053 e-mail: shil

Organization: R\&D, Human Systems, Org $4634 \quad$ Location: EROB 3WC1

Other Investigators: James Tortorelli, Gerald Harbour, Heather Medema, Julie Marble and James Byers

\section{PURPOSE OF THIS RESEARCH STUDY}

You are being invited to participate in a research study designed to examine the process of decision-making when presented with information. We are interested in how people acquire information while they make a decision. You are one of 8 INEEL employees being asked to participate.

\section{PROCEDURES:}

You will be asked to play a role as an aide to a senior legislator. You will be asked to examine information and then make a recommendation.

Before you begin the experimental task, you will be asked to complete two questionnaires about your attitudes and feelings. During the information viewing, you will periodically be prompted to report your decision making state - how close to a decision you are. The experiment may ask you a few questions about the current state of your decision. After you finish the experimental task, you will be asked to make your recommendation to the senior legislator and asked why you made that recommendation. You will also be asked questions about the experiment and your attitude and feelings toward it, and some basic information about yourself (for example, age).

Before you begin the experimental task, the experimenter will provide some training on the equipment being used and on the kind of task you will be asked to perform.

Your total participation should be approximately $1-1 \frac{1}{2}$ hours. 
In addition to questions asked before the task, during the task, and at the end of the experiment, any computer actions you may take will be recorded.

All of the data recorded during the study will be controlled by the Principal Investigator to ensure your privacy. The data will be kept in a locked cabinet, accessible only by the investigators. The data will be kept for three years.

\section{POSSIBLE RISKS OR DISCOMFORTS}

There is minimal risk associated with participation in this experiment. Minimal risk means that the potential for harm or discomfort is not greater than that encountered in daily living or during the performance of routine physical or psychological exams or tests.

\section{POSSIBLE BENEFITS AND COMPENSATION}

There is no direct benefit to you as a participant in this study, aside from increased knowledge about the task to be performed. However, a better understanding of the effects of different presentation methods and decision making may help improve efficiency in both government and civilian arenas.

You will be given a charge number - you will be paid your normal salary for participation in this research project.

\section{CONFIDENTIALITY}

Your identity in this study will be treated as confidential. All data will be identified only by a subject number; your name will not be associated with any data. The results of the study, including laboratory or any other data, may be published for scientific purposes but will not give your name or include any identifiable references to you.

However, any records or data obtained as a result of your participation in this study may be inspected by the sponsor, by any relevant governmental agency (e.g., U.S. Department of Energy), by the BBWI Institutional Review Board, or by the persons conducting this study, provided that such inspectors are legally obligated to protect any identifiable information from public disclosure, except as otherwise authorized or required by law.

\section{TERMINATION OF RESEARCH STUDY}

You are free to choose whether or not to participate in this study, and there is no penalty or loss of benefits if you decide not to participate.

You are also free to leave the study at any time without penalty or loss of benefits, but if you do so, you must notify the Principal Investigator.

Your participation in this study may be ended by the Principal Investigator at any time. The sponsor also reserves the right to terminate the study at any time.

\section{AVAILABLE SOURCES OF INFORMATION}


Any questions you may have about this study or about your rights as a research subject will be answered by the experimenter present or by the Principal Investigator:

Susan Hill Phone No.526-0053

\section{AUTHORIZATION}

I have read and understood this consent form, and I volunteer to participate in this research study. I understand that I will receive a copy of this form. I voluntarily choose to participate, but I understand that my consent does not take away any legal rights in the case of negligence or other legal fault of anyone who is involved in this study. I further understand that nothing in this consent form is intended to preempt any applicable Federal, state, or local laws regarding informed consent.

Participant Name (Printed or Typed)

Date

$\begin{array}{lll}\text { Participant Signature Date } & \text { D }\end{array}$

Principal Investigator or Present Experimenter Signature

Date

Witness Signature

Date 


\section{Appendix D \\ Positive Affect/Negative Affect Questionnaire}




\section{APPENDIX D: Positive Affect/Negative Affect Assessment Questionnaire}

This scale consists of a number of words that describe different feelings and emotions. Read each item and then mark the appropriate answer in the space next to that word. Indicate to what extent you feel this way right now, that is, at the present moment. Use the following scale to record your answers.

1

very slightly or

not at all
2

a little

interested

distressed

excited

upset

strong

guilty

scared

hostile

enthusiastic

proud
3

moderately

4

quite a bit

5

extremely

$\begin{array}{ll} & \text { irritable } \\ \text { alert } & \text { ashamed } \\ \text { inspired } \\ \text { nervous } \\ \text { determined } \\ \text { attentive } \\ \text { jittery } \\ \text { active } \\ \text { afraid }\end{array}$


Appendix E

Revised New Environmental Paradigm 


\section{APPENDIX E: New Environmental Paradigm}

Do you agree or disagree that:

(please check the appropriate box.)

1. We are approaching the limit of the number of people that earth can support.
strongly agree
mildly agree
unsure
mildly disagree
strongly disagree

2. Humans have the right to modify the natural environment to suit their needs.

strongly agree

mildly agree

unsure

mildly disagree

strongly disagree

3. When humans interfere with nature it often produces disastrous consequences.

strongly agree

mildly agree

unsure

mildly disagree

strongly disagree

4. Human ingenuity will insure that we do NOT make the earth unlivable.

strongly agree

mildly agree

unsure

mildly disagree

strongly disagree

5. Humans are severely abusing the environment.

strongly agree

mildly agree

unsure

mildly disagree

strongly disagree

6. The earth has plenty of natural resources if we just learn how to develop them.

strongly agree

mildly agree

unsure

mildly disagree

strongly disagree

7. Plants and animals have as much right as humans to exist.

strongly agree

mildly agree

unsure

mildly disagree

strongly disagree

8. The balance of nature is strong enough to cope with the impacts of modern industrial nations.

strongly agree

mildly agree

unsure

mildly disagree

strongly disagree

9. Despite our special abilities humans are still subject to the laws of nature. 
10. The so-called "ecological crisis" facing humankind has been greatly exaggerated.
strongly agree
mildly agree
unsure
mildly disagree
strongly disagree

11. The earth is like a spaceship with very limited room and resources.

strongly agree

mildly agree

unsure

mildly disagree

strongly disagree

12. Humans were meant to rule over the rest of nature.

strongly agree

mildly agree

unsure

mildly disagree

strongly disagree

13. The balance of nature is very delicate and easily upset.

strongly agree

mildly agree

unsure

mildly disagree

strongly disagree

14. Humans will eventually learn enough about how nature works to be able to control it.

strongly agree

mildly agree

unsure

mildly disagree

strongly disagree

15. If things continue on their present course, we will soon experience a major ecological catastrophe. 
Appendix F

Specific Task Instructions 


\section{APPENDIX F: Specific Task Instructions}

Scenario: You are a senior advisor to a national legislator. You have been asked to review this presentation and learn as much as you can about the topic. After reviewing the presentation, you will be asked to make two recommendations to the legislator. You will be asked to answer these two questions:

1. How would you characterize the issue described in the materials for the United States as a whole? (choose and circle one answer from each column)
1a.) not a problem
1b.) a very unimportant issue
a small problem
not an important issue
a moderate problem
an important issue
a large problem
a very important issue

2. You have a limited research budget in the legislator's office. The legislator has asked you, based on what you have learned from this material, if you would recommend spending how much, if any, of the research budget to study this issue and it's impact on the United States? What alternative action listed below would you recommend to the legislator (given that these are the only alternatives)?

spend none of the research budget

spend a small portion of the research budget

spend a moderate portion of the research budget

spend a significant portion of the research budget

Task: During the task, you will be periodically asked to report whether or not you have made a decision in regard to these two judgments. You will be asked "how close to a decision are you?" and "how certain of the decision are you?" You will be asked to indicate those answers on two rating scales. You will not be asked to report your decision. You may change your thinking at any time during the presentation.

Navigation through the presentation is as you would expect it - use the buttons to view the different parts of the presentation. You may view any part with an active button, even if you have viewed it before.

During your review of the presentation, you may see photos of people you recognize. During the development of the presentation, we asked local people to play certain roles - think of them as actors. They are not intended to trick or confuse you, but are acting in parts. Please accept the actors for who they are intended to be.

When you have completed reviewing and learning the material, please tell the experimenter. At that time, you will be asked some questions and will be asked for your decision. 
Appendix G

\section{Post-segment Decision Prompts}




\section{APPENDIX G: Post-segment Decision Prompt}

Prompt \# after

Please circle a vertical mark on the scale to indicate your response.

How close to a decision are you?

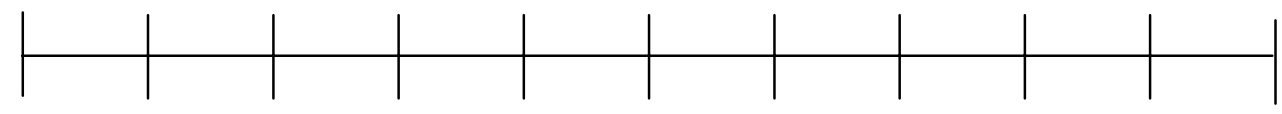

The decision is

About half

way to a

Have made a completely open decision

How certain are you that your current opinion will be your final decision?

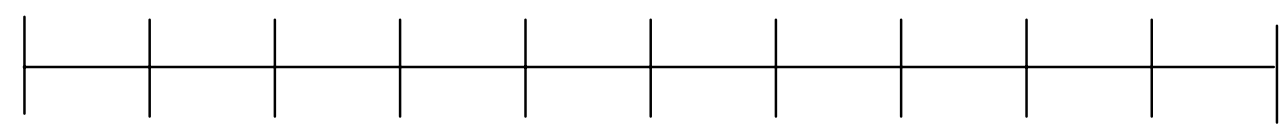

Not certain at

Half certain

$100 \%$ Certain of this decision

All 
Appendix $\mathrm{H}$

Interview Questions 


\section{APPENDIX H: Interview questions}

Below are the interview questions used between the segments. Not all questions were asked of every participant, and not all questions were asked between each segment. Each interview session lasted 5 to 10 minutes.

1. Is your opinion similar to what it was before you watched this segment?

2. Did any of the information in this segment have a strong affect on you or your decision?

2a. What information?

2b. In what way?

3. Do you feel that you know enough at this point to make a decision?

4. Are you looking for information to confirm an opinion, to disconfirm an opinion, or are you just looking for more information?

5. Do you feel you have more information on this phenomenon that when you began?

6. How valuable do you feel the information in that segment was toward making your decision?

7. Do you feel you have devoted enough time to studying this phenomenon?

a. How much more time do you feel you would spend researching this phenomenon?

b. Which is more critical to you in researching information; time or the value of the information?

c. Do you think that there is a trade off between the value of information and the time that you spend researching?

8. Are you looking for a specific type of information?

9. Do you feel involved in the presentation? (Are you having an emotional response to anything that you have seen?) 
Appendix I

Interview Transcripts 


\section{APPENDIX I: Interview transcripts}

Note: These are the experimenter's notes from the interviews with the participants. They do not represent transcripts of the interviews from audio or video recordings, and therefore, may not be exact quotations of the speakers.

\section{Participant 1}

Prompt 1 after Hypoxic Zone

Q: Have you formed an opinion? A: No.

Q: Are you looking for a specific type of information? A: Yes, hypoxic zone is actually related to pollution. I thought the gulf was cleaner than that. Is there another reason for the growth? I thought the Clean Air Act had caused improvement in the Gulf.

Q: Did any of the information or part of the presentation have a strong effect on you? A: Yes, the graphics of the size of the zone

Prompt 2 after Jubilee

Q: Have you formed an opinion? A: Starting to have an opinion. I want to know where the legislator is from

Q: Are you looking for a specific type of information? A: Yes, scientific, pollution

Q: Do you feel involved in the presentation or are you having an emotional response to anything you have seen? A: Concern

Q: Is your opinion similar to what it was before this segment? A: Similar opinion to before

Q: Did any of the information or part of the presentation have a strong effect on you? A: None in segment 2

Prompt 3 after Eutrophication

Q: Have you formed an opinion? A: Beginning to form

Q: Do you feel that you know enough right now to have an opinion? Could you decide if you had to? A: I would like more information

Q: Are you looking for a specific type of information? A: I would say that I am looking for information Q: Are you looking for information to confirm your opinion, disconfirm your opinion, or are you just looking for more information? A: I just want more information

Q: Do you feel involved in the presentation or are you having an emotional response to anything you have seen? A: Somewhat involved

Prompt 4 after Water mixing

Q: Is your opinion similar to what it was before this segment? A: Same opinion, same decision point. I am looking for more information. I need more information.

Q: Are you looking for information to confirm your opinion, disconfirm your opinion, or are you just looking for more information? A: I want to know what the connection to pollution is.

Q: Do you feel you have more information on this topic than when you began? A: More than when we began

Prompt 5 after Nutrient Supply

Q: Have you formed an opinion? A: Same opinion

Q: Did any of the information or part of the presentation have a strong effect on you? A: Size of the watershed

Q: Do you feel that you know enough right now to have an opinion? Could you decide if you had to? A: Probably not 
Q: What caused the jump in your decision? A: The amount of area in the watershed. I have to reconsider the questions. (Long pause) I have to think about agriculture as a business.

Q: Do you feel involved in the presentation or are you having an emotional response to anything you have seen? A: Concern

Q: Are you looking for information to confirm your opinion, disconfirm your opinion, or are you just looking for more information? A: Probably not any information that could help. Need solutions that focus on the effect of each farmer.

Prompt 6 after Nutrient Sinks

(Long pause before questionnaire)

Q: Is your opinion similar to what it was before this segment? A: Same opinion

Q: Do you think there is a tradeoff between the time you spend and the value of the information that you gain? A: Yes, but it is important to research into solutions

Prompt 7 after Algae Growth

Q: Is that your rating because it is the end of the presentation? Would your rating change if there were more information available? A: I know that we are out of information in the presentation. If there were more information it might change how much of the budget I would suggest spending.

Q: Do you feel involved in the presentation or are you having an emotional response to anything you have seen? A: Involved in the presentation, I was always involved in the presentation.

\section{Participant 2}

Prompt 1 after Hypoxic Zone

Q: Did any of the information or part of the presentation have a strong effect on you? A: No

Q: Are you familiar with the topic? A: I have heard of it

Q: Are you looking for information to confirm your opinion, disconfirm your opinion, or are you just looking for more information? A: Confirm my opinion. I need to know why it is important Q: Do you feel involved in the presentation or are you having an emotional response to anything you have seen? A: Not especially, just intellectual curiosity

Prompt 2 after Jubilee

(Took notes during presentation)

(Long pause)

Q: Is your opinion similar to what it was before this segment? A: Not much of an opinion

Q: Are you looking for a specific type of information? A: Yes, the ecological impact, and duration

Q: Are you looking for information to confirm your opinion, disconfirm your opinion, or are you just looking for more information? A: General information, I don't really have an opinion, there was nothing surprising

Q: Do you feel involved in the presentation or are you having an emotional response to anything you have seen? A: No, intellectual curiosity. I have several questions, so I am looking for specific information. Noticed that there is no emotion on the part of the actors.

Prompt 3 after Eutrophication

(Pause before completing questionnaire)

Q: Have you formed an opinion? A: Formed a decision / opinion

Q: Are you looking for information to confirm your opinion, disconfirm your opinion, or are you just looking for more information? A: Impact information, it affects the certainty of the decision. The historical and physical information does not help 
Q: Do you feel that you are spending too much time looking for information? A: I know what information that I want, but I don't know if the presentation will give that to me. So I can estimate how much money to budget, but I don't know how critical the problem is.

Q: Do you feel you have more information on this topic than when you began? A: Yes

Prompt 4 after water mixing

("Duh" opening comment after presentation, indicated that it was obvious information)

The information presented was obvious to the most casual observer. But the presentation doesn't allow me to change the focus of the discussion or ask questions.

Q: Do you feel involved in the presentation or are you having an emotional response to anything you

have seen? A: Yes, frustrated

Q: Is your opinion similar to what it was before this segment? A: Same point as last one

Q: Are you looking for a specific type of information? A: Yes, economic information. Presentation has too much historical information; I want the societal or biological impacts

Q: Do you feel that you know enough right now to have an opinion? Could you decide if you had to? A: Not enough information

Q: Did any of the information or part of the presentation have a strong effect on you? A: No, the

presentation is slow, we're not allowed to ask questions

\section{Prompt 5 after Nutrient Sinks}

(Long pause)

Q: Is your opinion similar to what it was before this segment? A: My mind is less made up, but I am more sure that I will go that way. I am more sure of $1 \mathrm{a}$ and $1 \mathrm{~b}$, but 2 is staying the same. If I knew that I would not get the information that I want, I would stop here

Q: Are you looking for a specific type of information? A: I did get some of the information that I am looking for

Q: Do you feel involved in the presentation or are you having an emotional response to anything you have seen? A: Less frustrated, still intellectual curiosity

Time/value: If there are other mechanisms available to get the information the time cost of information may not increase

Prompt 6 after Algae Growth

"Thank god it was quick. This presentation is slow enough for a 3 year old"

Q: Is your opinion similar to what it was before this segment? A: Same point

Q: Are you looking for a specific type of information? A: Still looking for specific information, this segment was a complete waste. I still have the same information that I have had the whole time. I don't feel like I am getting the important information.

Q: Do you feel that you know enough right now to have an opinion? Could you decide if you had to? A: No, not enough information. I want to know the current or future seriousness and trends. There is no alarming nature to this information.

Prompt 7 after Nutrient Supply

Q: Are you looking for a specific type of information? A: This did not give the information I am looking for. This decision is my decision because I am out of buttons. If there were more information here it would be the same as the previous point. I would go to another information source.

Q: How much more time would you be willing to spend looking for information? A: Less than I have so far, maybe 5 more minutes.

Q: Do you feel that you know enough right now to have an opinion? Could you decide if you had to? A: Not enough. Only doing it because I have to. 


\section{Participant 3}

Prompt 1 after Hypoxic Zone:

Were you familiar with this topic previously? No.

Q: Do you feel that you know enough right now to have an opinion? Could you decide if you had to? A: No

Q: Are you looking for information to confirm your opinion, disconfirm your opinion, or are you just looking for more information? A: No, I do not have any hypotheses

Q: Do you feel involved in the presentation or are you having an emotional response to anything you have seen? A: Yes. (Would not share what type of involvement felt).

Prompt 2 after Jubilee

Q: Is your opinion similar to what it was before this segment? A: I am about the same point as before. I would like to know more before I make a decision

Q: Did any of the information or part of the presentation have a strong effect on you? A: No, but I have only heard about the dolphin and whale beachings

Q: Do you feel that you know enough right now to have an opinion? Could you decide if you had to? A: I would like more information

Q: Do you feel involved in the presentation or are you having an emotional response to anything you have seen? A: Yes.

Prompt 3 after Eutrophication

Long pause before completing decision questionnaire

Q: Is your opinion similar to what it was before this segment? A: About the same as before. (Long pause.) I don't have any hypotheses, but I would like to know more about the effects of algae growth Q: Did any of the information or part of the presentation have a strong effect on you? A: No, but I do need more information.

Q: Are you looking for a specific type of information? A: I want to know what causes this whole thing

Prompt 4 after water mixing

(Long pause before completing questionnaire)

Q: Is your opinion similar to what it was before this segment? A: Yes, I am closer to making a decision. I could assume that I have made my decision at any time, but why not get the rest of the information if it is there and there is time available, especially if it doesn't take long.

Q: So, do you think there is a tradeoff between the time you spend and the value of the information that you obtain? A: It depends on the amount of time I am going to have to spend.

Q: Do you feel you have more information on this topic than when you began? A: Yes

Q: Do you feel that you know enough right now to have an opinion? Could you decide if you had to? A: Yes, but I want to look for more information

Q: Do you feel involved in the presentation or are you having an emotional response to anything you have seen? A: Yes.

Prompt 5 after Nutrient supply

(Pause while considering questionnaire.)

Q: Is your opinion similar to what it was before this segment? A: No, this is about the same as before

Q: Are you looking for a specific type of information? A: Yes, I have some questions about the movement of the dead zone, and the time course of the phenomenon, so I guess I am looking for certain information.

Q: Do you feel involved in the presentation or are you having an emotional response to anything you have seen? A: I am not concerned, but I am curious because I hadn't heard of this before. So it is sort of intellectual curiosity 
Q: Do you feel that you know enough right now to have an opinion? Could you decide if you had to? A: I want more information; generally I try to accumulate as much information as I can before I make a decision

Prompt 6 after Nutrient sinks

Q: Is your opinion similar to what it was before this segment? A: It's solidifying, partially because there is only 1 button left

Has your decision changed much since we started? It has stayed about the same type of decision and the amount of funds to budget

Q: Do you feel that you know enough right now to have an opinion? Could you decide if you had to? A: I would take the last bit

Prompt 7 after Algae growth

(Indicated that final segment did not contain any new information.) Without additional information there is no reason for me to change my decision. If there were more information available, I might change my rating

Q: Do you feel involved in the presentation or are you having an emotional response to anything you have seen? A: I am just wondering why I have never heard of this.

I think I just formed my decision as I went along.

\section{Participant 4}

Prompt 1 after Hypoxic Zone

Q: Are you familiar with this topic? A: I think I have heard of it. Is it related to red tides?

Q: How involved do you feel in the presentation? A: I am anxious to hear the presentation because I want to know what causes this.

Q: Do you have any questions that you are looking for the answers to? A: I want to know what the cause of it is, should we do something about it? What are the drivers?

Q: Do you feel involved in the presentation or are you having an emotional response to anything you have seen? A: I am a little frustrated because of the lack of information that was presented.

Prompt 2 after Jubilee

Q: Is your opinion similar to what it was before this segment? A: It's the same point.

Q: Are you looking for information to confirm your opinion, disconfirm your opinion, or are you just looking for more information? A: There is a significant piece of the data missing; what is causing this. I want to know what can be done about this.

Q: Do you feel involved in the presentation or are you having an emotional response to anything you have seen? A: I feel involved mostly because I am frustrated because the presentation is not directed to answering my questions.

Prompt 3 after Eutrophication

Q: Is your opinion similar to what it was before this segment? A: That moved me away from my decision. There were a few tidbits in that segment and the presentation may give me more Generally, I have specific information that I want to get quickly. If I don't get that information it would significantly affect my ability to make a decision.

Prompt 4 after Water Mixing

Q: Is your opinion similar to what it was before this segment? A: It has moved, also just because of the time I had to think about it. It's the same direction as earlier. 
Q: Did any of the information or part of the presentation have a strong effect on you? A: That segment had a strong effect, that it is dependent on mixing.

Prompt 5 after Nutrient Supply

Q: Is your opinion similar to what it was before this segment? A: Both are a little higher. The value of that segment was limited.

Q: Do you think there is a tradeoff between the amount of time you spend looking for information and the value of that information? My time is more valuable than the information from that segment.

Q: Do you currently have enough information to make a decision? A: There's not enough information yet to decide, but I feel like I am not going to get that information from this presentation.

Q: Is there a specific type of information that you are looking for? (No answer). Are you looking to confirm your opinion, disconfirm it, or are you just looking for more information? A: I am looking for information to disconfirm my decision.

Prompt 6 after Nutrient Sink

Q: Is your opinion similar to what it was before this segment? A: About the same point. There was some useful information; somewhat disconfirming my decision but it was not strong.

Q: Do you have enough information at this point to make a decision if you had to? A: I have enough information; I would like more information, but I probably won't get it since there is only one button left. It would be better if it would get directly to the point. I am close enough right now to make a decision. Q: How much more time would you spend to get information? A: I would only spend a little more time, if I had the table of contents for the presentation and could pick and choose what information I got. The information so far has been sketchy, only 2 of the segments were worth spending time on. A couple of the segments were useless and I have to assume that the rest of the segments are at the same level.

Prompt 7 after Algae Growth

Q: Is your opinion similar to what it was before this segment? A: Since the presentation is done, I am at $100 \%$, if it were not the end it would only back up a notch. I would hope for more useful information but I am pessimistic about it. The information was not useful enough.

Time/value: There is never a set amount of time that I am willing to spend. I usually go to the point where I am hearing over again information that I already got or until I have exhausted all the likely sources. The value of the information governs the time I am willing to spend.

\section{Participant 5}

Prompt 1 after Hypoxic Zone

Q: Are you familiar with this topic? A: No

Q: Do you feel involved in the presentation or are you having an emotional response to anything you have seen? A: Curious

Q: Did any of the information or part of the presentation have a strong effect on you? A: No, I just want to know if it is man-made or natural

Prompt 2 after Jubilee

Q: Is your opinion similar to what it was before this segment? A: Moving toward a decision

Q: Did any of the information or part of the presentation have a strong effect on you? A: That it is a natural phenomenon

Q: Do you feel that you know enough right now to have an opinion? Could you decide if you had to? A: Getting close, I could form an opinion but I want more information

Q: Are you looking for information to confirm your opinion, disconfirm your opinion, or are you just looking for more information? A: Open minded. I am looking for information that could confirm or disconfirm. I guess I am testing hypotheses 
Prompt 3 after Eutrophication

Q: Is your opinion similar to what it was before this segment? A: Moved back (Decision reversal)

Q: Did any of the information or part of the presentation have a strong effect on you? A: The severity of the problem, and that people have caused. I am looking for more information on human impact

Prompt 4 after Water mixing

Q: Is your opinion similar to what it was before this segment? A: Up, in the same direction, same decision

There are several factors that affected; it's natural; people don't know enough about our impact, the regularity of the occurrences

Q: Do you feel involved in the presentation or are you having an emotional response to anything you have seen? A: Concern, what is the extent of our impact, not certain of our impact

Q: Do you feel that you know enough right now to have an opinion? Could you decide if you had to? A: Could stop here, but I will take any additional information

Prompt 5 after Nutrient Supply

Q: Is your opinion similar to what it was before this segment? A: About the same

Q: Did any of the information or part of the presentation have a strong effect on you? A: Human

farming contribution, but there is not much that you can do about that, so I am still open minded

Q: Are you looking for a specific type of information? A: Yes, how certain are the experts?

Q: Are you looking for information to confirm your opinion, disconfirm your opinion, or are you just looking for more information? A: To confirm my opinion, but I am open to being disconfirmed

Prompt 6 after Nutrient Sinks

Q: Is your opinion similar to what it was before this segment? A: About the same

Q: Did any of the information or part of the presentation have a strong effect on you? A: Harnessing the river; we can't change that.

Q: Are you looking for a specific type of information? A: Trying to determine the severity of the problem, so I need more information

Prompt 7 after Algae Growth

"That didn't help much"

Q: Do you feel that you know enough right now to have an opinion? Could you decide if you had to? A: Could form an opinion, but I still want more information

Q: Is there a tradeoff between the time you are spending and the value of the information? A: I have the time so I can look, but if it were hectic I may have to consider the value of the information

Q: Do you feel you have more information on this topic than when you began? A: Yes.

\section{Participant 6}

Prompt 1 after Hypoxic Zone

Q: Is this topic familiar to you? A: Somewhat familiar. I have never seen a jubilee, but I have heard of the dead water zone.

Q: Did any of the information or part of the presentation have a strong effect on you? A: When you have actually seen this in Galveston it has a strong impact.

Q: Do you feel involved in the presentation or are you having an emotional response to anything you have seen? A: Somewhat. When you know that there is nothing you can do about it as an individual it is frustrating.

Prompt 2 after Jubilee 
Q: Is your opinion similar to what it was before this segment? A: Still a little confused

Q: Did any of the information or part of the presentation have a strong effect on you? A: The fisherman and the stuff about fishing, but I knew where it was leading. Having seen dead water and knowing the cause made me unhappy.

Q: Do you feel involved in the presentation or are you having an emotional response to anything you have seen? A: Frustrated, not being able to do anything about it. It's a huge problem, but one person can't do anything about it.

Q: Are you looking for a specific type of information? A: Point out where the problem is, and the cause. How certain are they of the cause? Do they have any proposed solutions?

Prompt 3 after Eutrophication

Q: Is your opinion similar to what it was before this segment? A: No, it didn't move very far

Q: Did any of the information or part of the presentation have a strong effect on you? A: No, I already knew the information that they presented

Q: Do you feel that you know enough right now to have an opinion? Could you decide if you had to? A: I am looking for what they want you to do about it.

Prompt 4 after water mixing

Q: Is your opinion similar to what it was before this segment? A: Not far. I am not as confident of my decision

Q: Are you looking for a specific type of information? A: I am looking for the motivation to do more research. I want the causes explained. They have defined the problem. Are there potential solutions?

Prompt 5 after Nutrient Supply

Q: Is your opinion similar to what it was before this segment? A: It has moved, both of them. Used to work in the agricultural programs here. Worked on methods to reduce the excess nitrogen from the fields. We were able to identify exactly how much fertilizer to use on a single field to minimize the runoff.

Q: Is this a reversal from your earlier position? Yes

Q: Do you feel you have more information on this topic than when you began? A: No, this was not new information, I knew what was coming

Q: Do you feel that you know enough right now to have an opinion? Could you decide if you had to? A: I would like to know what else they have to say. I like to listen to the whole story.

Prompt 6 after Nutrient sinks

(Pause)

This was a change in the direction in the presentation. Now they are addressing multiple issues. We can't do research on what the Army has done to the Mississippi River. (Little confidence in the army corps of engineers.)

Q: Is your opinion similar to what it was before this segment? A: Little change

Q: Did any of the information or part of the presentation have a strong effect on you? A: Mostly a response to the army corps of engineers. They need to consider the consequences of their actions.

Q: Do you feel involved in the presentation or are you having an emotional response to anything you have seen? A: Raising emotion. What is the take home message from this?

Q: Do you feel that you know enough right now to have an opinion? Could you decide if you had to? A: If I had to, I could but I want to know if they have anything else to convey, but I doubt it.

Prompt 7 after algae growth

There was no new information in that segment, so my opinion hasn't changed. Not sure what the contribution of that segment. Not sure the presentation is done so leaving it over to less decided. 


\section{Participant 7}

Prompt 1 after Hypoxic Zone

Q: Are you familiar with this topic? A: I have heard of the Black Sea dead zone.

Q: Do you feel involved in the presentation or are you having an emotional response to anything you have seen? A: Curious

Q: Did any of the information or part of the presentation have a strong effect on you? A: No

Prompt 2 after Jubilee

Q: Is your opinion similar to what it was before this segment? A: Same point as before. "I'm not sure of this whole thing. Is it a true thing?"

Q: Did any of the information or part of the presentation have a strong effect on you? A: Squirming fish

Q: Do you feel that you know enough right now to have an opinion? Could you decide if you had to? A:

A little bit. What is the cause? What is the impact on the environment?

Prompt 3 after Eutrophication

Q: Is your opinion similar to what it was before this segment? A: It has moved. Realization that occurred, this is a water quality issue. It's the same basic opinion

Prompt 4 after Water Mixing

Q: Is your opinion similar to what it was before this segment? A: Same

Q: What was the value of the information? A: Ok. It was new information, but it wasn't what I was looking for. Have to see the whole picture. Getting more information is more important than the time spent, as long as I am not under time pressure

Q: Is your opinion open to change? A: It would have to be something drastic.

Q: Are you looking for information to confirm your opinion, disconfirm your opinion, or are you just looking for more information? A: More information, not looking to confirm or disconfirm my opinion. I know there is more information so I want it, and that limits me from making my final decision.

Prompt 5 after Nutrient Supply

Q: Is your opinion similar to what it was before this segment? A: Same point. That segment had a low value of information to my decision

Q: Did any of the information or part of the presentation have a strong effect on you? A: Average person doesn't realize the impact of all the farms, so the multiplication

Q: Do you feel you have more information on this topic than when you began? A: Yes

Q: Do you feel involved in the presentation or are you having an emotional response to anything you have seen? A: Concern for the water supply, all those drains, and the canals, and what people dump in the canals

Prompt 6 after Nutrient Sinks (watched twice, interviewed after second)

(Pause after first time through)

"I'm considering if that bought me anything" then replayed

Q: Is your opinion similar to what it was before this segment? A: Moved

Q: Did any of the information or part of the presentation have a strong effect on you? A: Wetland shrinkage was valuable. I had realized the value or known the importance of the role of wetlands. We have to value the environment as a whole and realize the impact of our actions

Prompt 7 after Algae Growth

1. Same point 
Q: How much more time would you be willing to spend if there were more information? A: I would go through all the information I had, if it ends here, I would base my decision on what I have. I can't say what the value of more information would be because I don't know what the information would be.

\section{Participant 8}

Prompt 1 after Hypoxic Zone

Q: Are you familiar with this topic? A: No.

Q: Do you feel involved in the presentation or are you having an emotional response to anything you have seen? A: Surprised.

I am not typically concerned about environmental issues.

Prompt 2 after Jubilee

Q: Is your opinion similar to what it was before this segment? A: It was a little move.

Q: Did any of the information or part of the presentation have a strong effect on you? A: The eyewitness and the news story. I am wondering if this is a real issue. Sometimes the media will just make an issue just to increase readership.

Q: Do you feel that you know enough right now to have an opinion? Could you decide if you had to? A: No.

Q: Do you feel involved in the presentation or are you having an emotional response to anything you have seen? A: Just a little curious

Prompt 3 after Eutrophication

(Pause)

Q: What are you considering? I am wondering how isolated this phenomena. What state does this legislator represent? It is not an issue for Idaho. E: The legislator can represent whichever state makes you most happy.

Q: Is your opinion similar to what it was before this segment? A: It did move more. I am assuming that the legislator is some local official, and this mostly seems to affect the Gulf of Mexico. It doesn't seem to affect the US as a whole.

Q: Do you feel that you know enough right now to have an opinion? Could you decide if you had to? A: No, I would like to go on.

Q: Are you looking for information to confirm your opinion, disconfirm your opinion, or are you just looking for more information? A: Yes, I have specific questions. What is the effect on the whole country?

I would say I am looking to confirm my opinion.

Prompt 4 after Water Mixing

Q: Is your opinion similar to what it was before this segment? A: It has moved.

Q: How valuable was that segment toward making your decision? A: It was interesting, but there was no information about the effect on the US as a whole. My decision moved because of the information about storms and winter breakup. It seems like an isolated phenomenon that has a natural factor that corrects it.

Q: Are these different factors than you have been considering? A: I have been considering the same factors the whole time.

Prompt 5 after Nutrient Supply

Q: Is your opinion similar to what it was before this segment? A: I am more sure of this decision. Farming occurs across the US, and all farmers use fertilizer, so its getting into the water has a big impact on the environment. That is kind of what I have been looking for, but I need to stay focused on the 
hypoxic zone and eutrophication, not the effects of farming on the water supply. I don't want to get sidetracked.

Q: Are you looking for a specific type of information? A: Not really, who ever put this together has done a lot of research, so I feel the need to review it all but if there had not been so much work put into the presentation then I would make my decision right now. More information about the impact on the nation as a whole could affect my opinion, but the topic names don't indicate that they will.

Prompt 6 after Nutrient Sinks

Now the presentation has spread the issue out to other communities that are affected. That is what I was looking for earlier.

Q: Is your opinion similar to what it was before this segment? A: I have backed off some. I am not revising my opinion; there was some information that was contrary to what I thought, so I have just backed off some.

Q: How valuable was that information on a scale of 1 - 10? A: 8. I wish I had known earlier that everyone up river was affected.

Q: Do you feel you have more information on this topic than when you began? A: Yes.

Prompt 7 after Algae Growth

Q: Is your opinion similar to what it was before this segment? A: Same general direction, I just had to consider the focus of the questions.

Q: If there were more buttons, would that change your rating? A: If there were more information available it would change how I rated my decision. But I would still want to know how widespread is it. There are nutrient sources all across the US, so there is a large region affected. I have to consider what is the real issue. I don't want to get side tracked, but I think that broadens the question. There are nutrient problems in all rivers. I have to assume the focus is on the hypoxic zone in the Gulf of Mexico.

Q: Did any of the information or part of the presentation have a strong effect on you? A: No.

Q: If there were more information would that change your rating? A: My rating would back off from completeness.

Q: How much more time would you be willing to spend? A: Whatever it takes. 
Appendix $\mathrm{J}$

Post-experiment Recommendation Task 


\section{APPENDIX J: Post-experiment Recommendation task}

You are a senior advisor to a national legislator. You have been asked to review this presentation and learn as much as you can about the topic. You will be asked questions about the content after reviewing presentation. After reviewing and learning as much as you could from the presentation, you are being asked to make recommendations to the legislator. The first question is:

1a. How much of a problem is the issue of eutrophication for the United States as a whole?

$$
\begin{aligned}
& \text { not a problem } \\
& \text { a small problem } \\
& \text { a moderate problem } \\
& \text { a large problem }
\end{aligned}
$$

1b. How certain are you of this characterization? (circle a vertical line on the scale)

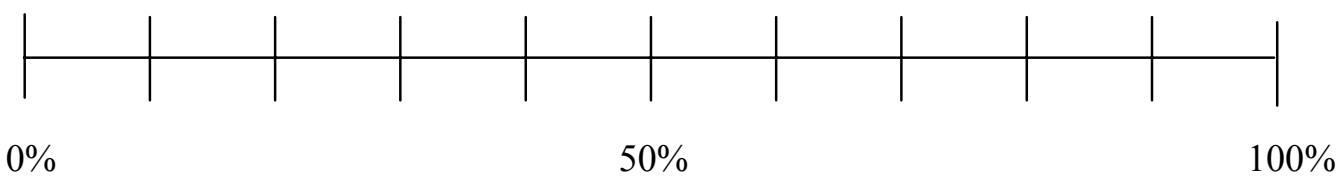

1c. How important an issue is eutrophication for the United States as a whole?

a very unimportant issue

not an important issue

an important issue

a very important issue

1d. How certain are you of this characterization? (circle a vertical line on the scale)

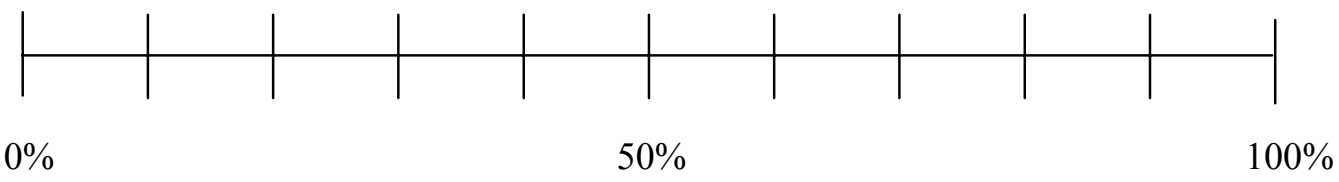

Please write your answers to these questions. (If needed, identify the question and continue on the back.)

2a. Why do you choose those characterizations?

2b. What influenced this characterization? What information did you use to decide on this characterization?

2c At what point in the presentation did you decide on this characterization?

2d. What was the process of deciding on this characterization? What was your thinking as you made this characterization? 
3a. You have a limited research budget in the legislator's office. The legislator has asked you, based on what you have learned from this material, if you would recommend spending how much, if any, of the research budget to study the issue of eutrophication and it's impact on the United States? What alternative action listed below would you recommend to the legislator (given that these are the only alternatives)?

(please circle your answer)

spend none of the research budget

spend a small portion of the research budget

spend a moderate portion of the research budget

spend a significant portion of the research budget

3b. How certain are you of this recommendation? (mark a vertical line on the scale)

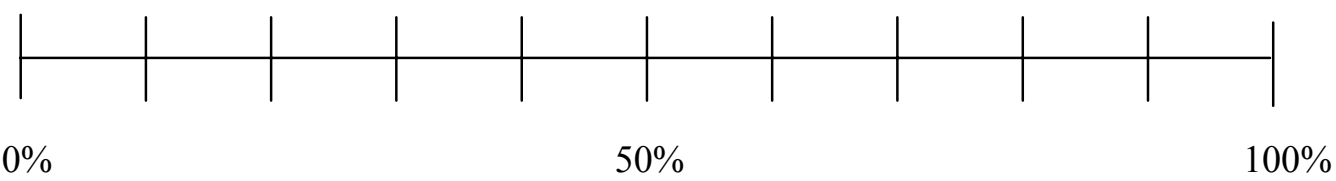

Please write your answers to these questions. (If needed, identify the question and continue on the back.)

3c. Why do you choose that alternative?

3d. What influenced this recommendation? What information did you use for this recommendation?

3e. At what point in the presentation did you decide on this recommendation?

3f. What was the process of deciding on this recommendation? What was your thinking as you made this recommendation? 


\section{Appendix K \\ Post-experiment Credibility Questionnaire}




\section{APPENDIX K: Post-experiment Credibility Questionnaire}

We are interested in your opinions about the presentation as a whole.

Do you agree or disagree that:

(please check the appropriate box.)

1. The material was believable.

$\begin{array}{llll}\text { strongly agree } & \text { mildly agree } & \text { unsure } & \text { mildly disagree }\end{array}$

2. The material tried to appeal to my emotions.

$\begin{array}{llll}\text { strongly agree } & \text { mildly agree } & \text { mildly disagree } & \text { strongly disagree }\end{array}$

3. Before this presentation, I was familiar with the topic and information presented.

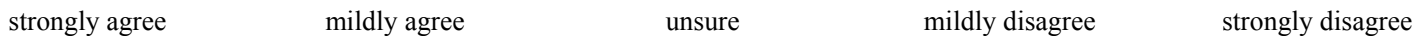

4. The material was based on scientific fact.

strongly agree

mildly agree

unsure

mildly disagree

mildly disagree

unsure

strongly agree

mildly agree

strongly agree

mildly agree

unsure

mildly disagree

strongly disagree

7. The material presented was accurate.

strongly agree

mildly agree

unsure

mildly disagree

strongly disagree

8. The material was confusing.

strongly agree

mildly agree

unsure

mildly disagree

strongly disagree

9. The material was truthful. 
10. The developers of the presentation carefully evaluated the information presented.

strongly agree

mildly agree

unsure

mildly disagree

strongly disagree

11. This was a balanced presentation.

strongly agree

mildly agree

unsure

mildly disagree

strongly disagree

12. This was a complete presentation.

strongly agree

mildly agree

unsure

mildly disagree

strongly disagree

13. The contents of the presentation were credible.

strongly agree

mildly agree

unsure

mildly disagree

strongly disagree

14. The material presented appears to be scientifically certain.

strongly agree

mildly agree

unsure

mildly disagree

strongly disagree

15. I have a personal stake in the topic presented.

strongly agree

mildly agree

unsure

mildly disagree

strongly disagree 
We are interested in your opinions about the presentation style and format.

Do you agree or disagree that:

(please check the appropriate box.)

1. I enjoyed this presentation style and format more than the "average" presentation style and format.

strongly agree

mildly agree

2. I felt excited by the style and format.

strongly agree

mildly agree

unsure

3. The style and format was distracting.

strongly agree

mildly agree

unsure

4. I felt motivated by the style and format.

strongly agree

mildly agree

unsure

mildly disagree

strongly disagree

5. I really enjoyed the style and format.

strongly agree

mildly agree

unsure

mildly disagree

strongly disagree

6. This style and format was boring.

strongly agree

mildly agree

unsure

mildly disagree

strongly disagree

7. The style and format was informative.

strongly agree

mildly agree

unsure

mildly disagree

strongly disagree

8. The style and format was stimulating. mildly agree mildly disagree

strongly disagree 
9. The style and format was annoying.

$$
\text { strongly agree }
$$$$
\text { mildly agree }
$$

unsure

10. I really liked the style and format. strongly agree mildly agree unsure mildly disagree

strongly disagree

11. The style and format effectively presented the information. mildly disagree

strongly disagree

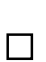

mildly agree

unsure

mildly disagree

strongly disagree

12. The style and format was engaging. mildly agree unsure strongly agree mildly disagree

strongly disagree 
Please consider the presentation as a whole, including content, information, style and format. Please write your answers to these questions. (If needed, identify the question and continue on the back.)

1. What did you think of the material that was presented?

2. Did you believe the material? Do you believe it was based on scientific fact? Why?

3. Do you think it was intended to appeal to your emotions? Why? In what way?

4. Was there anything about the presentation that you thought was particularly effective? particularly well done?

5. Was there anything about the presentation that you thought was particularly not effective? particularly poorly done?

6. Any other comments? 
Appendix L

Post-experiment Demographic Questionnaire 


\section{APPENDIX L: Post-experiment Demographic Questionnaire}

Please write your answers in the blank spaces or circling your answer, as appropriate.

1. Age:

2. Gender: Male Female

3. Please circle the phrase that describes your highest level of education:

Never attended school

Some grade school

Completed grade school

Some high school

Completed high school

Some college

Completed college two-year degree (associate's degree)

Completed college four-year degree (bachelor's degree)

Some graduate work

Completed Masters degree

Completed Doctorate degree

4. Job title:

5. Area of expertise (what area you work in, for example, waste management, software development, public affairs)

6. Circle the phrase that most describes your political ideology:

Liberal

Slightly Liberal

Middle of the Road

Slightly Conservative

Conservative 
L-1 
Appendix M

Experiment Script and Agenda 


\section{APPENDIX M: Experiment Script and Agenda \\ Set Up before Subject Arrives}

chair, desk

computer (for multimedia presentation)

Paper work, pencil, pen

"Experiment in Progress" Sign

\section{Welcome, Agenda}

Welcome. Thanks for coming. My name is

Have a seat. Here's the agenda of what will be happening in this session.

Read through agenda. Point out the PI/experimenter's names. Point out the charge \#.

\section{Informed Consent}

The first order of business is to read and complete the Informed Consent form. This describes the research and other information. Please read it carefully and ask as many questions as you would like before you decide whether to participate. Please initial and date the bottom of each page, and then sign on the last page, if you're willing to participate.

\section{Experimental Purpose.}

We are interested in looking at how people acquire information while the make a decision. So you'll be presented with some environmental information, and then you'll be asked to make a decision about it. At various points during the presentation of the information, I will ask you to indicate how close you are to making a decision.

\section{Pre-Test Questionnaires}

Before the task, there are a few questionnaires I would like to complete now. The instruction for each is at the top of the page.

The first is a questionnaire about how you feel at this moment.

Subject is given and completes the pre-test PANAS.

The second is a questionnaire about your attitudes.

Subject is given and completes the pre-test NEP.

Thanks.

\section{Experiment Task and Procedures}


The equipment you will be using will be using is this computer and mouse.

The computer works the same way as a standard PC. Use the left mouse click to click on buttons.

When you have completed the task, you will be asked to complete some questionnaires and answer some questions about your participation in the experimental task.

Any questions?

\section{Specific Instructions}

Now you will be given specific instructions for the experimental task.

Subject is given the specific instruction for the decision making experiment.

Read through the instruction with them.

Are there any questions?

You may begin when you are ready.

\section{Completing the Post-Experiment Questionnaires and Debrief}

Now there are a few questionnaires I would like you to complete now. The instruction for each is at the top of the page.

The first is a questionnaire about how you feel at this moment.

Subject is given and completes the post-test PANAS.

The second is a questionnaire about your attitudes.

Subject is given and completes the post-test NEP.

Here is the Recommendation questionnaire.

Subject is given and completes the post-test Recommendation Questionnaire.

Now I have a few questions I'd like you to answer.

Subject is given and completes the post-test credibility/likeability Questionnaire and Demographics information sheet.

\section{Closing Remarks}

That completes the experiment.

Thanks again for participating. 
Please, do not discuss the details of this experiment with anyone else until we have completed the entire study, which will be the end of August. We don't want any potential participants to be biased by prior information.

Here is your copy of the signed Consent form. The charge number and principal investigator's phone number are on your initial agenda.

Before we end, any other questions or comments? 


\section{Welcome to the Human-System Simulation Laboratory}

We appreciate your willingness to participate in our experiment.

You are authorized to charge this experiment time to charge number G341T5425

\section{Today's Agenda}

Consent Form

Questionnaires

Introduction to Experiment and Procedures

Experimental Task

Debrief

Principal Investigator: Susan Hill, x6-0053

Experimenters: Julie Marble, Heather Medema 